\title{
A FUNCTIONAL ANALYSIS OF THE JAW MECHANISM IN THE SLING-JAW WRASSE
}

\author{
S.C. BURGESS ${ }^{1}$, J. WANG ${ }^{1}$, A.C. ETOUNDI ${ }^{1}$, R. VAIDYANATHAN ${ }^{1} \&$ J.D. OLIVER ${ }^{2}$ \\ ${ }^{1}$ Department of Mechanical Engineering, Bristol University, UK. \\ ${ }^{2}$ Department of Biology, Liberty University, USA.
}

\begin{abstract}
Sling-jaw wrasse can deploy their mouths forward at high speed to catch prey and collect food. The forward swimming of the fish and the deployment of the jaw mechanism has been simulated using numerical analysis of the equations of motion. Computed tomography and reverse engineering have been used to obtain accurate geometrical and mass data of an actual sling jaw wrasse including the jaw mechanism. The analysis shows that maximum snout acceleration is up to $10.7 \mathrm{~g}$, whereas the maximum fish acceleration is up to $0.25 \mathrm{~g}$, thus showing the advantage of having the deployable snout. The analysis also shows that maximum snout acceleration is highly dependent on the size of the fish. Small fish of $7.5 \mathrm{~cm}$ length have a maximum snout acceleration of up to $10.7 \mathrm{~g}$, whereas large fish of $35 \mathrm{~cm}$ length have a maximum snout acceleration of up to $5.2 \mathrm{~g}$. The analysis may help to explain why deployable jaws are not seen on fish greater than about $35 \mathrm{~cm}$ in length. Hypothetical predator-prey chasing scenarios show that the deployable mouth gives the sling-jaw wrasse a very significant advantage when the prey is in close range. The sling-jaw wrasse demonstrates that linkage mechanisms enable a high degree of optimisation of movement to be achieved in a deployment mechanism. Biomimetic applications of the jaw mechanism are briefly discussed.

Keywords: 4-bar mechanisms, deployment mechanisms, reverse engineering, biomimetics.
\end{abstract}

\section{INTRODUCTION}

Sling-jaw wrasse (Epibulus insidiator) lives in tropical coral reef areas all over the world and lives in water depths between 1 and 40 metres. The adult sling-jaw wrasse can be up to about $35 \mathrm{~cm}$ in length. The sling-jaw wrasse gets its name from its slinging jaws that can be protruded forward at high speed. A sling-jaw wrasse with mouth retracted and deployed is shown in Fig. 1(a). Part of the linkage is a 4-bar parallelogram mechanism as shown in Fig. 1(b). The parallelogram 4-bar mechanism enables the mouth to protrude by a significant distance. This allows the fish to catch prey and to reach into cracks. The fast deployment of the mouth also creates a suction effect that draws food or prey into the mouth.

The telescopic mouth is very effective at catching prey since moving a mouth is much faster than moving the entire body of the fish through water by swimming. This is especially true when the fish is stationary since swimming from a standing start in water is inherently slow and inefficient.

Linkage mechanisms like 4-bar mechanisms allow a high degree of optimisation of motion and force together with freedom in choosing the location of actuators. Therefore, it is not surprising that linkage mechanisms are commonly seen in both engineering and nature. Examples of 4-bar mechanisms in engineering include the 4-bar Ackerman steering mechanisms in cars, hinge mechanisms in double glazed window units, hinge mechanisms in up-and-over garage doors and clamp pliers. Linkage mechanisms are seen in nature in the mammalian knee joint [2, 3], bird wing joints [4], insect wings [5], snake jaws [6] and fish jaws [7].

In both engineering and nature, the benefits of the linkage mechanisms must outweigh the costs associated with producing and accommodating the mechanism. In the case of fish, there are obvious benefits in having a highly dexterous jaw. Since fish do not have hands or feet, they rely on their mouths to catch and grasp food. In terms of cost, 4-bar mechanisms are relatively easy to accommodate because they are compact and lightweight. Therefore it is not surprising that linkage mechanisms are commonly found in fish.

(C) 2011 WIT Press, www.witpress.com

ISSN: 1755-7437 (paper format), ISSN: 1755-7445 (online), http://journals.witpress.com

DOI: 10.2495/DNE-V6-N4-258-271 
(a)
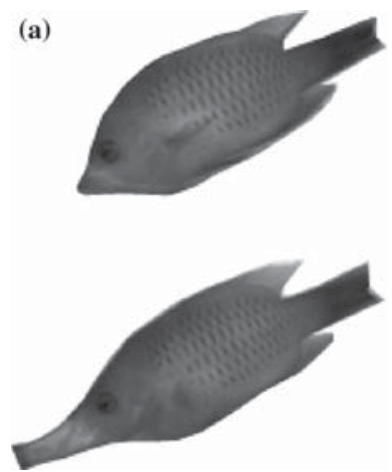

(b)
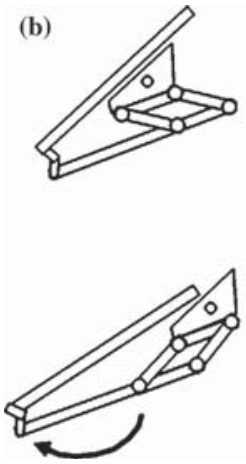

Figure 1: (a) Sling-jaw wrasse [1]. (b) Schematic diagram of the jaw mechanism.

This paper presents a functional analysis of the linkage mechanism in the jaw of the sling-jaw wrasse in order to assess the mechanical performance of the linkage mechanism in terms of speed, acceleration and ability to catch prey. Another purpose of the study is to see if there are lessons for the optimal design of deployment systems in engineering. Analogies and applications of the jaw deployment mechanism to engineering are briefly discussed at the end of the paper.

\section{FUNCTION-MEANS TREE OF THE JAW MECHANISM}

Function-means trees can be used to visualise multiple functions, objectives and solutions in a complex mechanism or system. The components and mechanisms in natural organisms often have multiple functions, so function-means trees are particularly applicable. Function-means trees have been previously produced for bird feathers [8] and trees [9].

A function-means tree for the sling-jaw wrasse is given in Fig. 2. At the top of the tree is the highest level objective of saving energy. This is one of the most basic objectives for any creature since it directly relates to survivability. The means by which this high level objective is met is shown by the branches of the tree with the detailed solutions shown at the root level of the tree.

In the case of the jaw mechanism of the sling-jaw wrasse, there are two main ways of saving energy as shown in the second level of the tree. One is to increase the effectiveness in getting food so that less effort is required to obtain the daily food needs. Figure 2 shows two ways of increasing the effectiveness of getting more food. One is to have a fast deployable mouth (with suction effect) that increases the chances of capturing a prey. The second is to have a narrow protruding mouth that can fit into long narrow cracks. The second main branch of the tree shows that another way of saving energy is to reduce the need to travel to stationary food. Swimming in water is energy consuming and so energy can be saved by having a deployable mouth to collect stationary food.

A parallelogram 4-bar deployment mechanism is a good solution for all four different branches of the tree because it is compact and lightweight. One of the reasons why the parallelogram 4-bar mechanism is compact is because the actuator muscles can actuate the mechanism from behind. This means that the muscles can be located behind the mouth.

The function-means tree in Fig. 2 shows that there are multiple functions and objectives of the 4-bar mechanism and that all of the objectives are met with the parallelogram 4-bar mechanism. It illustrates that 4-bar mechanisms are sophisticated devices that can achieve several objectives simultaneously. 


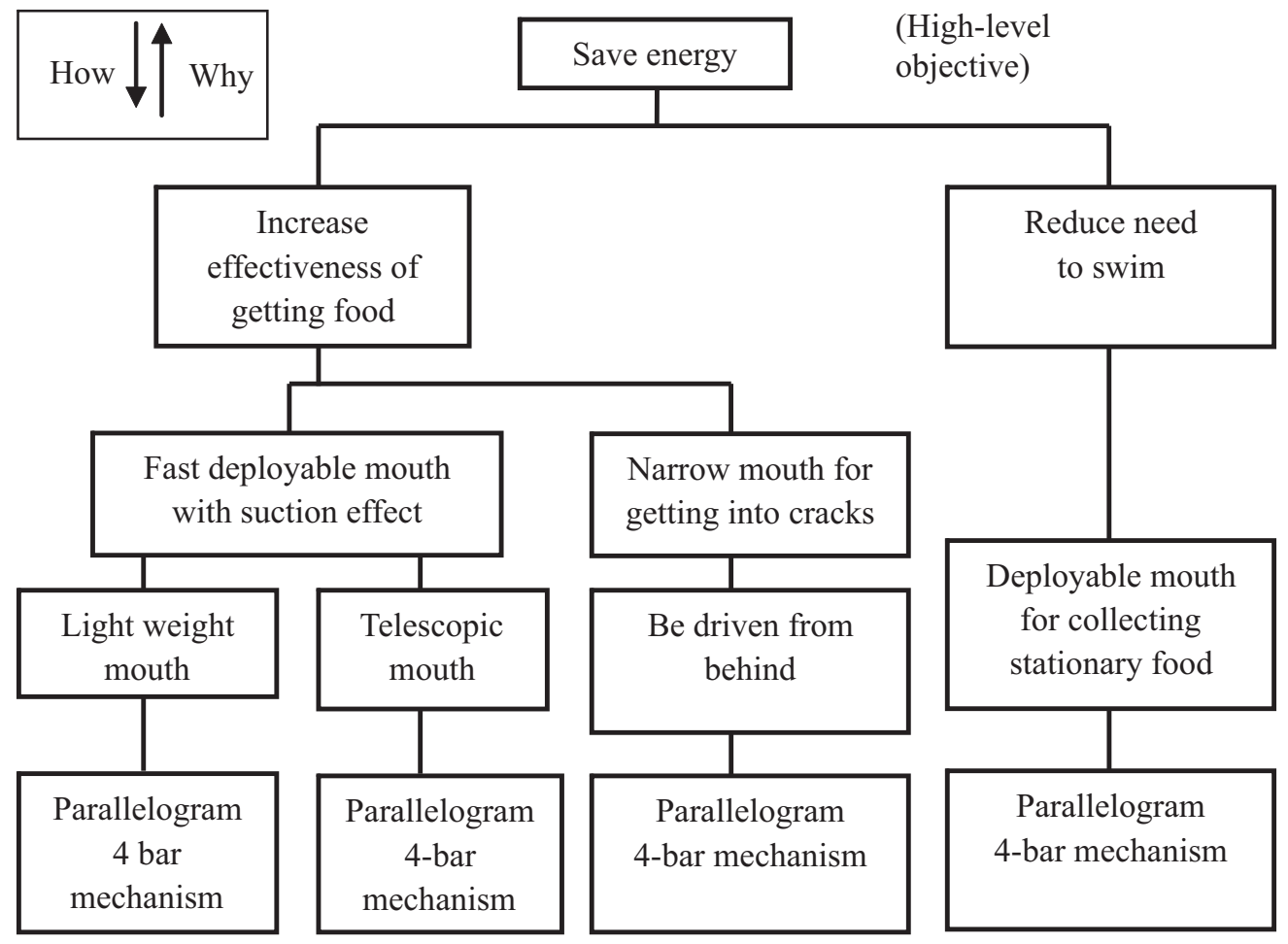

Figure 2: Function-means tree for the jaw of the sling-jaw wrasse.

\section{REVERSE ENGINEERING OF THE JAW BONES OF A SLING-JAW WRASSE}

Reverse engineering was carried out in order to generate an accurate computer model of the geometry. Reverse engineering has the ability to transform very complex shapes into digital models that can be used for computer presentation and analysis. Reverse engineering was carried out by scanning a sling-jaw wrasse with a Nikon X-TEK, computed tomography (CT) scanner.

\subsection{CT scans of wrasse jaws}

A CT scan of the wrasse with retracted mouth is shown in Fig. 3. A CT scan of a wrasse with a deployed mouth is shown in Fig. 4. The pictures clearly show the three-dimensional nature of the jaw mechanism. A design detail that has not been highlighted before in the literature is a guide on top of the nose consisting of two arched sections of bone. This double arch structure acts as a linear guide for the top part of the jaw.

\subsection{Conversion of CT scans into CAD models}

The raw CT scans were imported into a Vg-studio Max package as a point cloud. The point cloud was manually edited and manipulated and then a polygonisation was carried out to get a solid model as shown in Fig. 5. The CAD model was used to derive mass data for the numerical modelling presented in Section 4. 


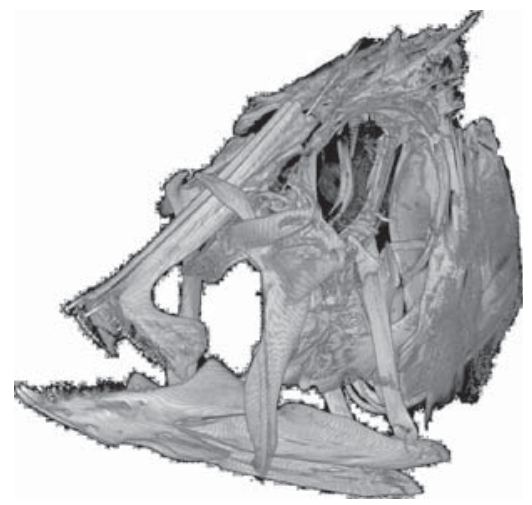

Figure 3: CT scan of wrasse with retracted mouth.

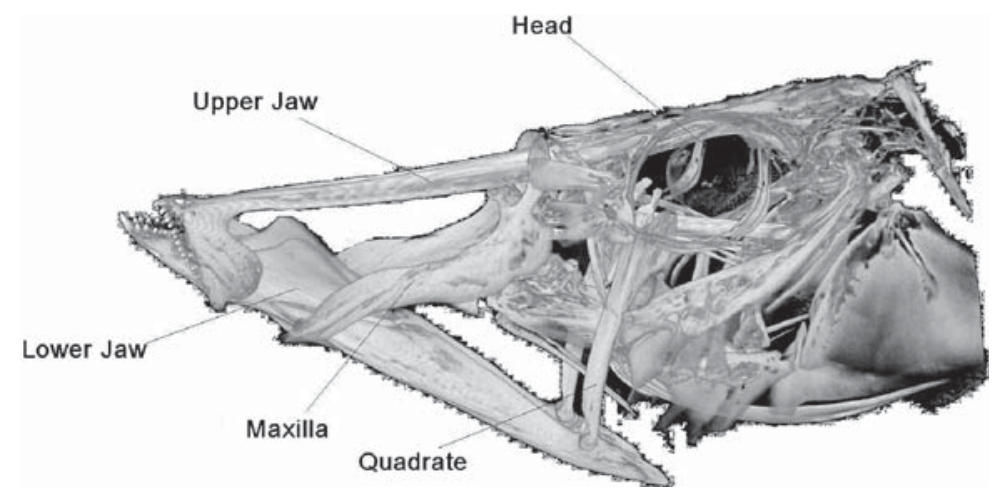

Figure 4: CT scan of wrasse with deployed mouth.

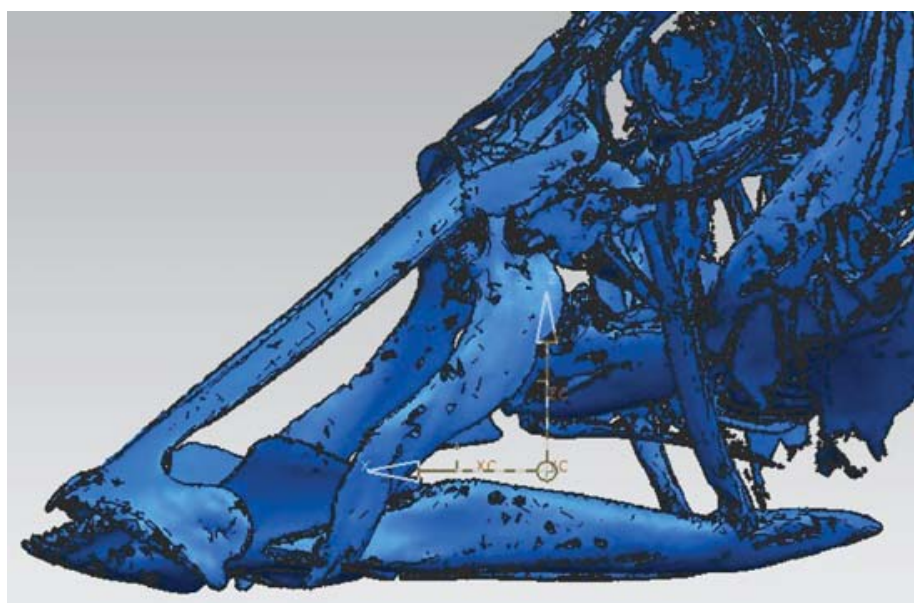

Figure 5: CAD model produced by reverse engineering. 

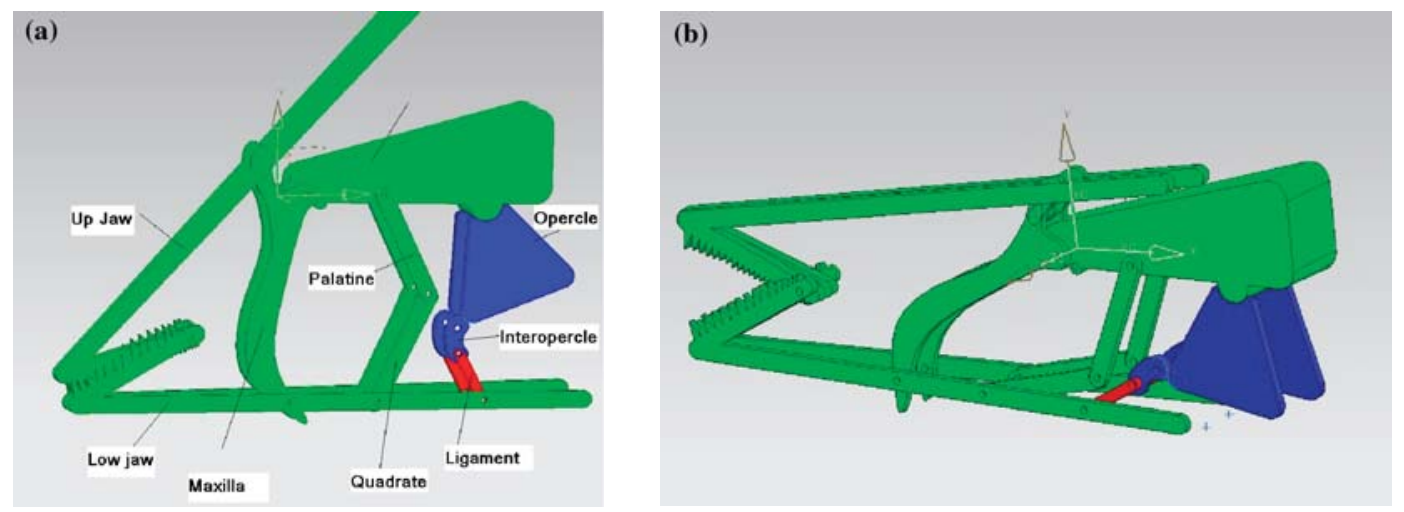

Figure 6: CAD model: (a) Retracted position; (b) Deployed position.

The reverse engineered CAD model was also used to create a simplified CAD model to identify the principal components. The parts shown in Fig. 6 are similar to those identified by other researchers [10-13].

\section{NUMERICAL MODEL OF THE JAW MECHANISM}

In order to predict the motion of the fish during swimming and the jaw during deployment, a numerical model was created on the basis of equations of motion for the fish and for the deployable part of the snout.

Creating equations of motion for fish locomotion is difficult because swimming under water involves complex interactions between the fish and water. In addition, fish are very variable in terms of shape and physical properties. However, it is possible to carry out a first order of magnitude analysis using the form drag equation for a streamlined body passing through a fluid and using typical physical data for fish muscles. In addition, various factors can be used to take into account the efficiency of swimming at different speeds.

The equations of motion given in this section are based on the basic equation of motion, $\mathrm{s}=\mathrm{ut}+0.5 \mathrm{at} \mathrm{t}^{2}$ using an incremental time step of $\delta \mathrm{t}$. The incremental distance for the whole wrasse swimming through water was calculated using the following equation of motion:

$$
\delta s_{f}=u_{f} \delta t+0.5\left[\frac{F_{f} a}{b m_{f}}-\frac{k_{f} u_{f}^{2}}{b m_{f}}\right] \delta t^{2}
$$

where

$$
\begin{aligned}
& a=0.3+0.5 \frac{u_{f}}{u_{f-\max }} \\
& b=1.2-0.2 \frac{u_{f}}{u_{f-\max }} \\
& k_{f}=0.5 \rho C_{d-f} A_{f-f}
\end{aligned}
$$


where $\delta s_{f}$ is the incremental forward distance moved by the fish, $u_{f}$ is the velocity of the fish, $m_{f}$ is the mass of the fish, $\delta$ t is a time step, $\rho$ is the water density, $\mathrm{C}_{\mathrm{d}-\mathrm{f}}$ is the drag coefficient of the fish and $A_{\text {f-f }}$ is the frontal area of the fish.

The factor $a$ (eqn (2)) takes into account that the efficiency of fish propulsion typically ranges from 0.3 at low speeds to 0.8 at maximum speed [14]. The factor $b$ (eqn (3)) takes into account that when a fish accelerates hard from a standing start, a significant amount of water is accelerated with the fish, which is equivalent to around $20 \%$ of the mass of the fish [15]. The factor $k_{f}$ (eqn (4)) takes into account the form-drag resistance that varies with the square of the speed $u_{f}$ There is an assumption that form-drag dominates over friction drag.

The maximum velocity, $u_{f-\max }$ is calculated by equating the power available with the power required for motion. In fishes, the proportion of the body mass consisting of muscles available for propulsion is typically around $40 \%$ [16]. Therefore, the power available, $P_{a}$, is given by $P_{a}=0.4 m_{f} P_{m}$, where $P_{m}$ is the power density of the fish muscle. The power required at the maximum swimming velocity is given by $P_{\text {req }}=0.5 \rho \mathrm{C}_{\mathrm{d}} \mathrm{A}_{\mathrm{f}} u_{f-\max }{ }^{2}$. Therefore, the maximum fish velocity is given by:

$$
u_{f-\max }=\left(0.8 \frac{m_{f} P_{m}}{\rho C_{d-f} A_{f-f}}\right)^{1 / 2}
$$

The drag coefficient was taken as 0.2 and the power density was taken as $P_{m}=75 \mathrm{~W} / \mathrm{kg}$. These values are similar to those used by other researchers $[14,17]$. The propulsive force at the maximum speed $F_{f-\text { max }}$ is given by $\mathrm{P}_{\mathrm{a}} / \mathrm{u}_{\mathrm{f}-\max }$.

One particular challenge with the equations of motion for living creatures is to specify the muscle force at zero and slow speeds. This is because if force is calculated from the power available, then the forces are unrealistically high at low speeds. In fact, the force would be predicted to be infinite at zero speed. An estimate of the real force available at different muscle speeds can be made by assuming that the force at zero speed is twice that at maximum power speed and that the force decreases linearly from zero speed to maximum speed. Hill has reported that the maximum muscle force at low speeds in animals is almost twice that of the force at maximum speed [18]. Such a profile is also characteristic of many DC motors between zero speed and maximum power speed. Therefore in our simulation the force is given by eqn (6):

$$
F_{f}=\left[2-\frac{u_{f}}{u_{f_{-\max }}}\right] F_{f-u \max }
$$

Using similar assumptions, the equation of motion for the snout is given by:

$$
\delta s_{s}=u_{s} \delta t+0.5\left[\frac{a F_{s}}{m_{s}}-\frac{k_{s} u_{s}^{2}}{m_{s}}\right] \delta t^{2}
$$

where

$$
\begin{gathered}
k_{s}=0.5 \rho C_{d_{-s}} A_{f-s} \\
F_{s}=\left[2-\frac{u_{s}}{u_{s-\max }}\right] F_{s-u \max }
\end{gathered}
$$


An adult sling-jaw wrasse was analysed with a CT scanner in order to get measurements and proportions for one characteristic length of fish. The sling-jaw wrasse was $17.5 \mathrm{~cm}$ in length, with a frontal area of $11.5 \mathrm{~cm}^{2}$ and with a mass of 100 grams. The mouth had a frontal area of $1.44 \mathrm{~cm}^{2}$ and could extend by up to $3.4 \mathrm{~cm}$ and had a mass of $2 \mathrm{~g}$. The mass of muscle driving the snout was assumed to be five times the mass of the bones in the snout. This assumption was based on observations of the jaw structures. The fish and snout were scaled geometrically in the analysis in order to predict the motion of larger and smaller adult wrasse.

\section{VELOCITY PROFILE OF FISH AND SNOUT}

The equations of motion were first solved for a fish length of $17.5 \mathrm{~cm}$. The snout deployment time for a fish length of $17.5 \mathrm{~cm}$ and for a distance of $25 \mathrm{~mm}$ is about $25 \mathrm{~ms}$ as shown in Fig. 7 . This time is consistent with time measurements of the actual jaw closing time of $C$. trilobatus during feeding of about $20 \mathrm{~ms}$ [19-21]. Figure 7 also shows that the amount of time it would take the fish to swim forward $25 \mathrm{~mm}$ from a standing start is about $170 \mathrm{~ms}$. Therefore the snout gives a very large speeding up factor of about 7 times to move $25 \mathrm{~mm}$. In practice the advantage is greater because in $170 \mathrm{~ms}$, the prey would have had time to start moving away (see Section 7). If the sensing and reaction time of prey is more than $25 \mathrm{~ms}$, then the sling-jaw wrasse can easily catch the prey.

Results of the forward movement of fish for different fish lengths are shown in Fig. 8. Results of snout deployment for different fish lengths are shown in Fig. 9. The results for different fish lengths were obtained by scaling the results for $\mathrm{L}=17.5 \mathrm{~cm}$.

The velocity profile for the fish is given in Fig. 10 for different lengths of fish. The velocity profile of the snout is shown Fig. 11 for different lengths of fish. The results show that the snout reaches a speed of $1 \mathrm{~m} / \mathrm{s}$ in $10-20 \mathrm{~ms}$ where the fish takes about $350-700 \mathrm{~ms}$ to get to this speed. That is a difference of 35 times which can have a significant influence on the effectiveness of hunting.

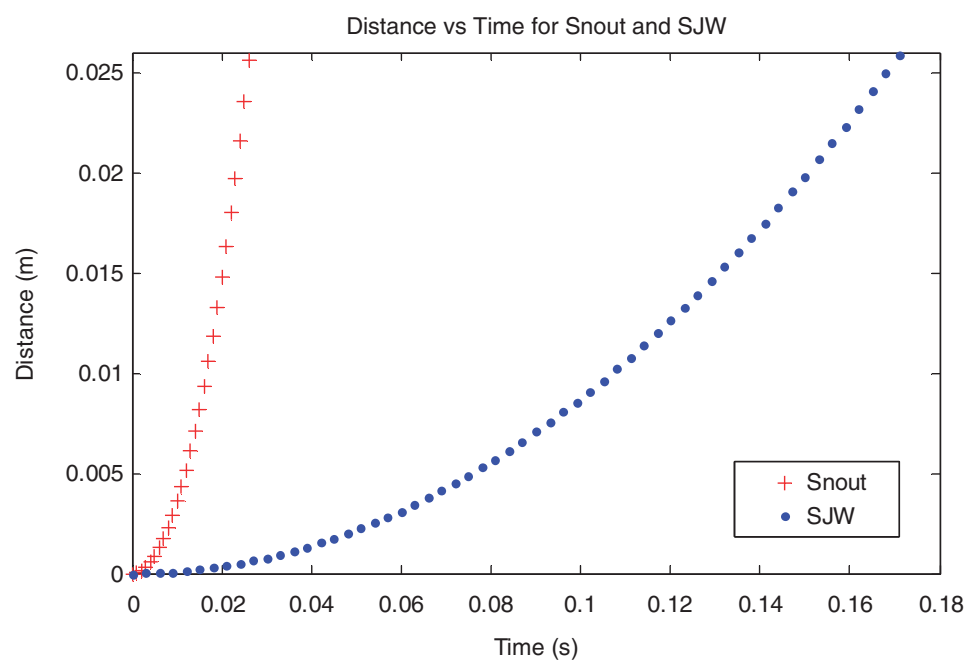

Figure 7: Forward movement of snout and fish for $\mathrm{L}=17.5 \mathrm{~cm}$. 


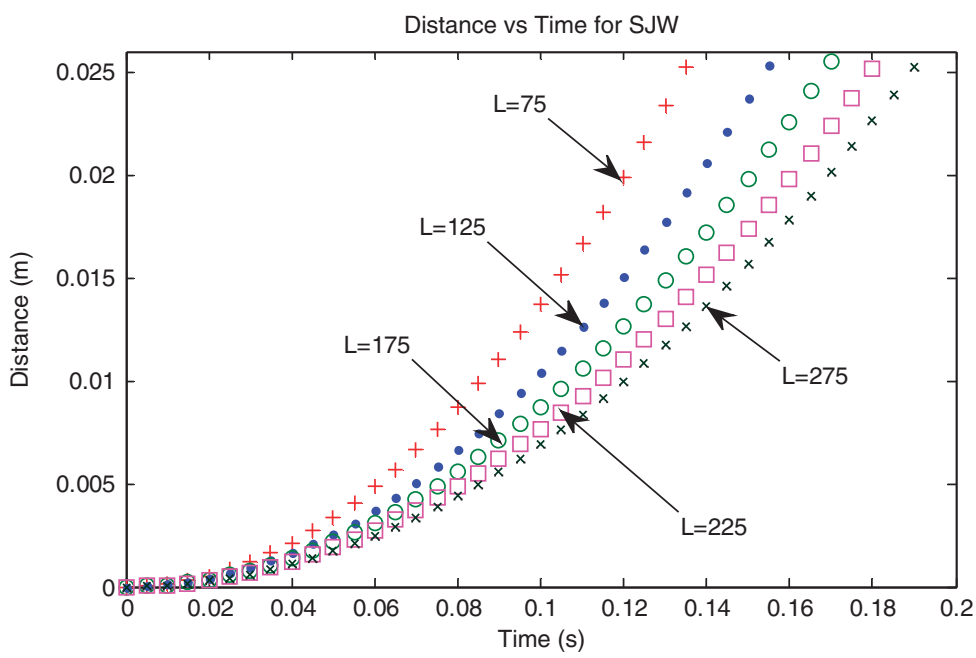

Figure 8: Forward movement of fish for different fish lengths.

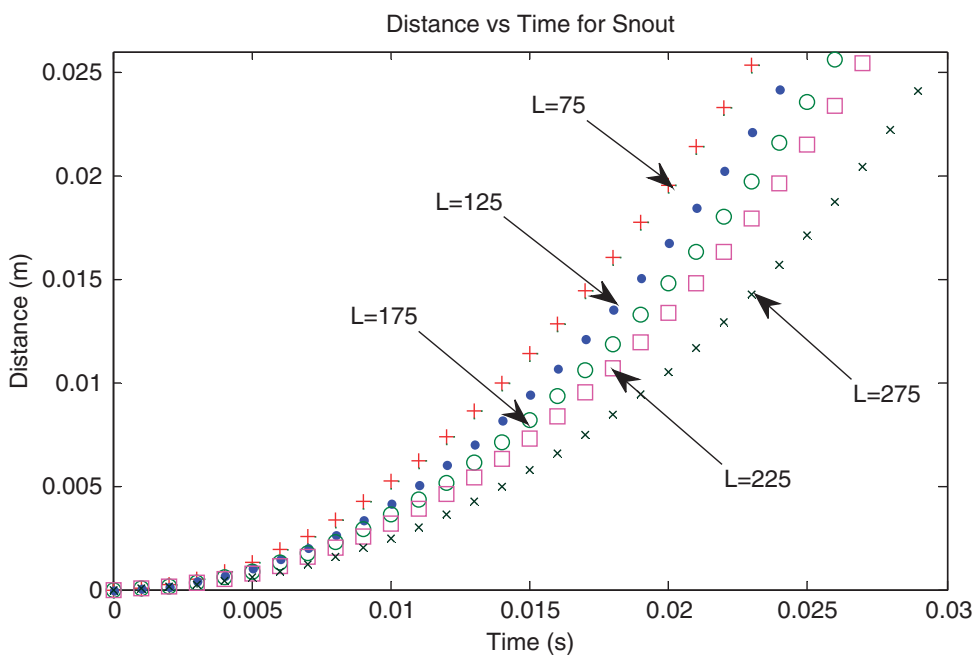

Figure 9: Forward movement of snout for different fish lengths.

\section{MAXIMUM ACCELERATION OF FISH AND SNOUT}

Figure 12 shows how the maximum acceleration of the snout and fish varies for different lengths of fish. The acceleration of the snout is greater than the fish by around 40 times for all lengths of fish. This demonstrates that the snout is a great advantage to the sling-jaw wrasse.

The predicted maximum acceleration of $10.7 \mathrm{~g}$ for small wrasse is similar to an experimental measurement of just over $10 \mathrm{~g}$ by Westneat for a small wrasse [7, 20]. It also shows that maximum snout acceleration is highly dependent on the size of the fish. Small fish of $7.5 \mathrm{~cm}$ length have a maximum snout acceleration of up to $10.7 \mathrm{~g}$, whereas large fish of $35 \mathrm{~cm}$ length have a maximum 


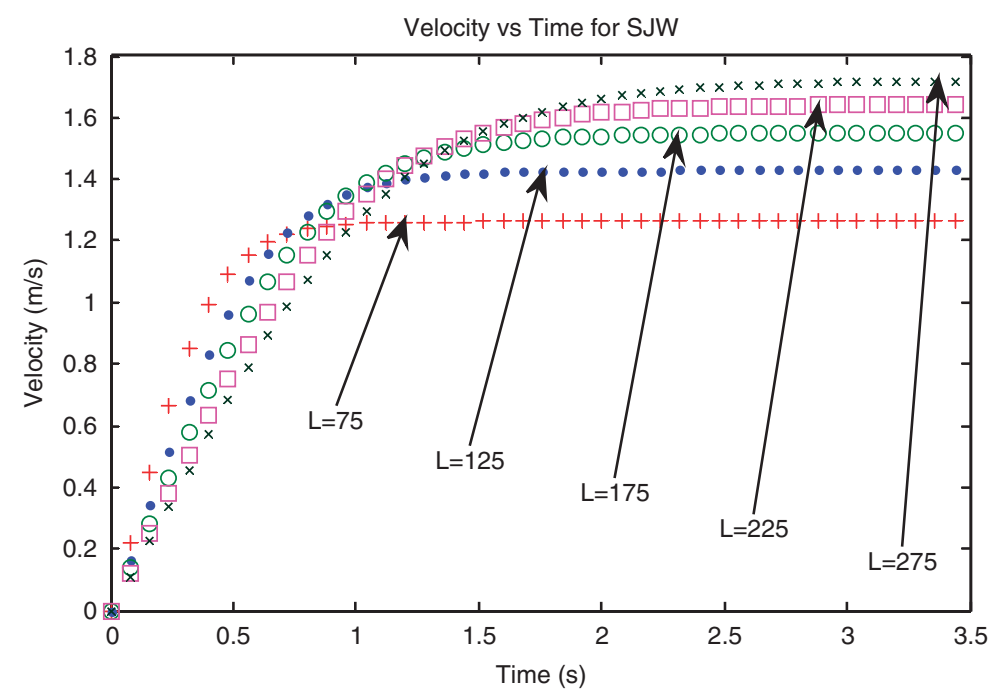

Figure 10: Velocity profile of fish.

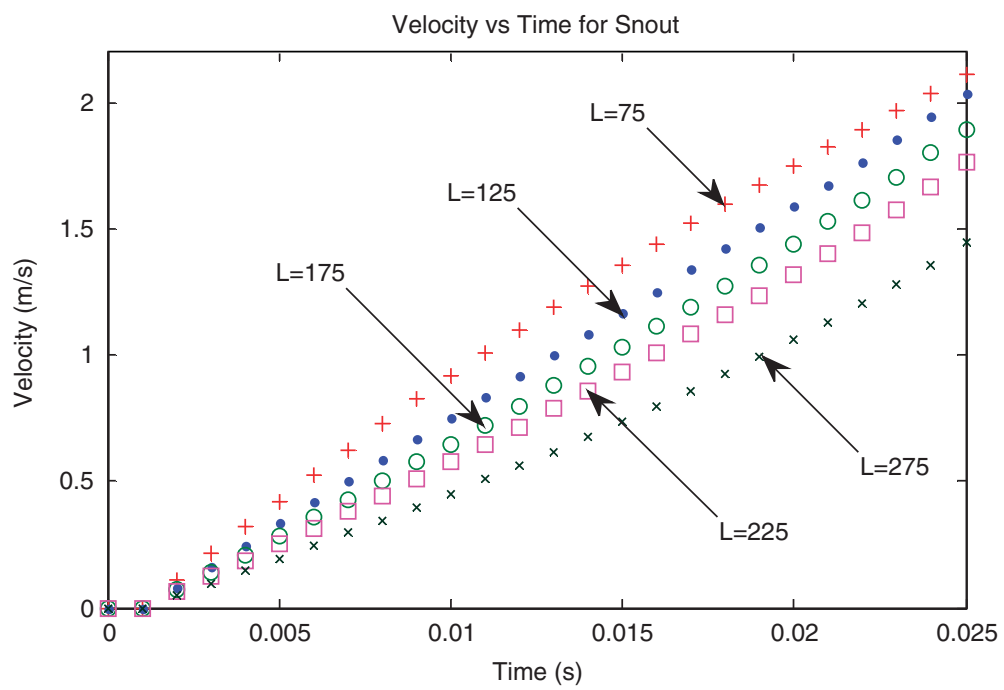

Figure 11: Velocity profile of snout.

snout acceleration of up to $5.2 \mathrm{~g}$. The analysis may help to explain why deployable jaws are not seen on fish greater than about $35 \mathrm{~cm}$ in length.

It is possible to predict the shape of the curves in Fig. 12 by analysing the scaling effect on the maximum acceleration. For a given drag coefficient, given power density and given shape of fish, the maximum acceleration of the fish and snout is a function of the size of the fish. From the 


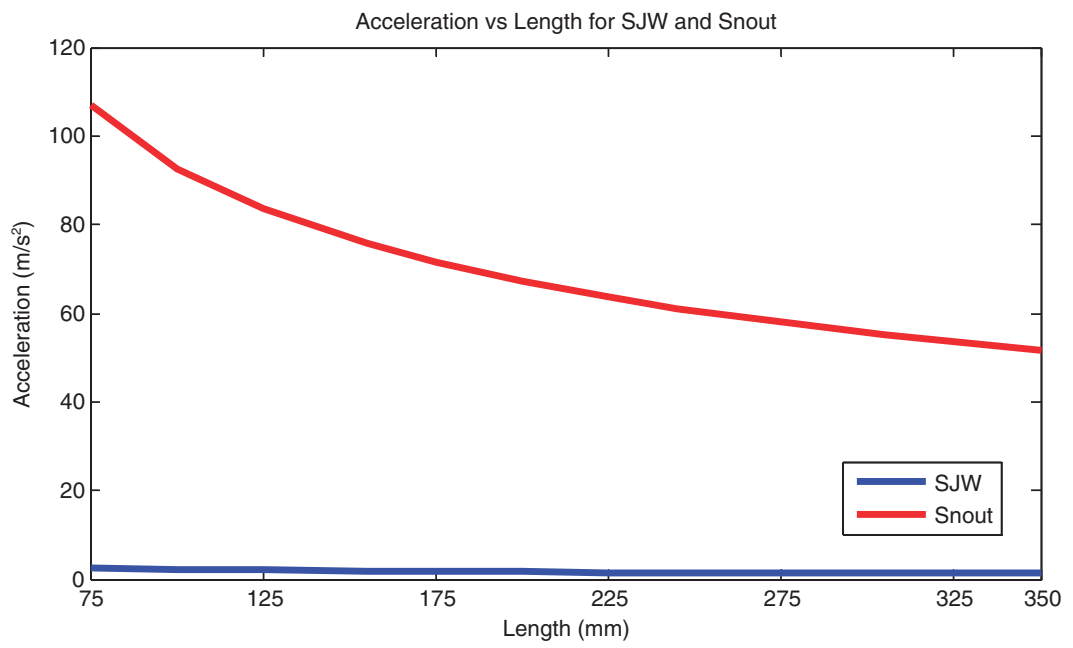

Figure 12: Acceleration of snout and fish versus length of fish.

equations of motion (eqns (1) and (5)), the maximum acceleration occurs at zero speed and is given by:

$$
a_{\max }=\frac{F_{f-\text { intial }}}{m_{f}}=K_{1}\left[\frac{m_{f}}{m_{f}}\right]\left[\frac{A_{f}}{m_{f}}\right]^{1 / 2}=K_{1}\left[\frac{A_{f}}{m_{f}}\right]^{1 / 2}
$$

where $\mathrm{K}_{1}$ is a constant. It is also possible to define the acceleration in terms of a characteristic length, $L$ by using a different constant, $\mathrm{K}_{2}$ :

$$
a_{\max }=K_{2}\left[\frac{L^{2}}{L_{3}}\right]^{1 / 2}=K_{2}\left[\frac{1}{L}\right]^{1 / 2}
$$

The accelerations shown in Fig. 12 are indeed inversely proportional to $\mathrm{L}^{1 / 2}$ which is consistent with eqn (11).

\section{AN EXAMPLE PREY-CHASING SCENARIO}

When prey sense that there is a threat from a sling-jaw wrasse (SJW), they will attempt to swim away. In order to assess the benefit of the fast jaw protrusion, this section considers a hypothetical chasing scenario. In the simulation, the SJW and prey were assumed to start in a stationary position with the prey $1 \mathrm{~cm}$ ahead of the SJW as shown in Fig. 13. The prey was assumed to be geometrically similar to the wrasse but five times smaller in length. The predator and prey are assumed to have the same muscle power density, same drag coefficient and the same shape of body. Flow for both fish was assumed to be turbulent with form drag dominating. The suction effect was not modelled.

The simulation considered the case of the sling jaw chasing prey without using the mouth and the case of just using the mouth to catch prey. In the first simulation, the SJW and prey both accelerate at maximum capacity until the SJW catches the prey. In the second simulation, the SJW deploys its 

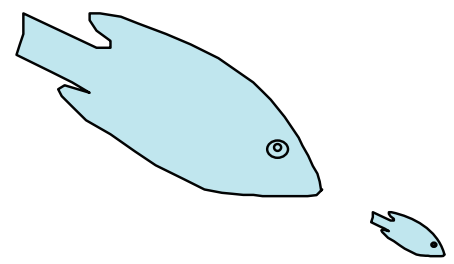

Figure 13: Wrasse pursuing prey.

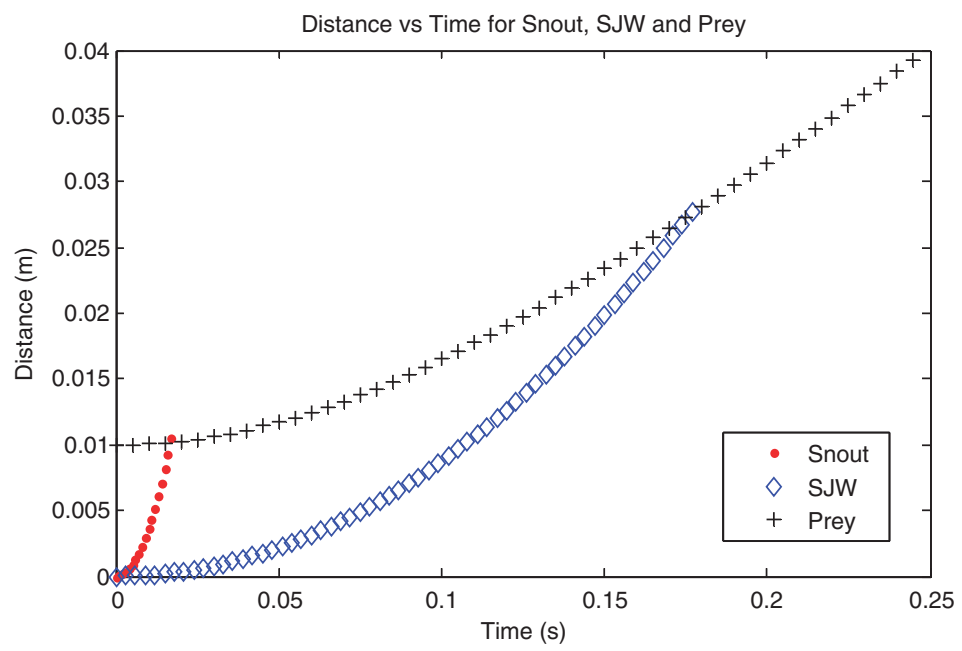

Figure 14: Prey interception profile with and without use of snout.

jaw without swimming whilst the prey accelerates to escape at maximum capacity. Figure 14 shows the results of the two simulations in order to show the benefit of using the snout. When the snout is not used the Wrasse takes about $180 \mathrm{~ms}$ to catch the prey, whereas when the snout is used the SJW takes only about $18 \mathrm{~ms}$ to catch the prey, which is a factor of about 10 times faster. The advantage of the snout is more pronounced than in Section 5 because the prey is moving away whilst being chased.

\section{ENERGY SAVING INVOLVED IN MOUTH PROTRUSION}

When eating stationary food, the sling jaw has a choice of whether to swim right up to the food or to swim up to a point and then extend its jaw. Using the snout can save energy because it is much easier to move than moving the whole fish over a small distance. The energy required in each case can be calculated by integrating force times the distance travelled. The energy required for swimming $25 \mathrm{~mm}$ for the fish length of $17.5 \mathrm{~cm}$ is approximately 0.45 Joules. In contrast, the energy to move the snout is approximately 0.0095 Joules. So there is big energy saving in using the snout of around 50 times. Of course there may be other factors that affect the trade-off such as the fish needing to swim to allow the gills to function. However, it is clearly advantageous for the sling jaw to have the option of using the snout to save energy. 


\section{DISCUSSION AND ANALOGIES WITH ENGINEERING}

\subsection{Deployable mouths in nature}

Deployment of mouths and tongues is common in nature. Fish-eating birds like herons and swans deploy their necks to quickly grab fish out of the water. Some snakes deploy their bodies in order to bite or catch prey. Many types of creature have long deployable tongues including frogs, humming birds, woodpeckers, butterflies and bats. The ability to deploy a mouth or tongue is therefore an important strategy in nature for capturing prey.

\subsection{Parallelogram 4-bar mechanisms in engineering}

In engineering, parallelogram 4-bar mechanisms are often used in linear bearings and actuators. One reason is that 4-bar mechanisms contain rotary bearings that are generally simpler and more reliable than linear bearings. NASA has developed a linear bearing using a parallelogram 4-bar mechanism for a spectrometer mirror carriage. The reason for using the 4-bar mechanism was to avoid linear bearings [22]. Parallelogram 4-bar mechanisms have also been used in nanometer scale mechanisms to produce linear bearings [23]. Another advantage of using parallelogram mechanisms is that they enable the use of remote actuators for driving a hinge [24].

\subsection{Biomimetic applications of the sling-jaw mechanism}

The deployable mouth of the sling jaw represents a highly efficient linear deployment mechanism. This could form the basis of a bio-inspired design for robotic limbs, especially for underwater vehicles where an aerodynamic shape is required. There have been recent development studies on aquatic autonomous vehicles [25]. One of the purposes of these vehicles is to carry out underwater operations such as repair of oil rig equipment. The importance of these vehicles has been recently demonstrated with the oil spill disaster in the Gulf of Mexico. In such applications deployable grabbing mechanisms are required and so the sling-jaw wrasse could form the basis of a bio-inspired design. The suction effect of the sling-jaw wrasse could also have biomimetic applications in capturing rubbish or spilt oil.

The sling-jaw wrasse demonstrates the advantage of using a deployable structure to move a small distance compared to moving the whole body. This concept could have biomimetic applications in cleaning or harvesting. For example, swimming pools and reservoirs use robots for cleaning the bottom. Such robots could be made more efficient by using deployable cleaning rods.

\section{CONCLUSION}

Computed tomography and reverse engineering have enabled a clear three dimensional visualisation of the deployment mechanism in the sling-jaw wrasse to be revealed. The reverse engineering also enabled accurate mass data for the bones to be obtained. Numerical analysis predicts that the deployable mouth is 7 times faster at moving $25 \mathrm{~mm}$ compared to the whole fish swimming from a standing start. Hypothetical predator-prey chasing scenarios show that the mouth gives the sling-jaw a very significant advantage when the prey is in close range. The analysis shows that maximum acceleration is highly dependent on the scale of the fish. Small fish of $7.5 \mathrm{~cm}$ length have a maximum snout acceleration of up to $10.7 \mathrm{~g}$, whereas large fish of $35 \mathrm{~cm}$ length have a maximum snout acceleration of up to $5.2 \mathrm{~g}$. The analysis may help to explain why deployable jaws are not seen on fish greater than 
about $35 \mathrm{~cm}$ in length. The linkage mechanism in the sling-jaw wrasse is a sophisticated mechanism that enables fast linear actuation.

\section{ACKNOWLEDGEMENTS}

The authors would like to thank Kevin Skuse and Rolls Royce for use of their CT scanner.

\section{REFERENCES}

[1] Westneat, M.W., Linkage biomechanics and evolution of the unique feeding mechanism of Epibulus insidiator (Labridae: Teleostei). Journal of Experimental Biology, 159, pp. 165-184, 1991.

[2] Muller, M., A novel classification of planar four-bar linkage and its application to the mechanical analysis of animal systems. Biological Sciences, 351(1340), pp. 689-720, 1996. doi:http:// dx.doi.org/10.1098/rstb.1996.0065

[3] Bertomeu, J.M., Lois, J.M., Guillem, R.B., Pozo, A.P., Lacuesta, J., Mollà, C.G., L,una, P.V. \& Pastor, J.P., Development of a hinge compatible with the kinematics of the knee joint. Prosthetics and Orthotics International, 31(4), pp. 371-383, 2007. doi:http://dx.doi. org/10.1080/03093640601095842

[4] Bellairs, A.A. \& Jenkin, C.R., The skeleton of birds. Biology and Comparative Physiology of Birds, Vol. 1, ed. A.J. Marshall, Academic Press: New York, pp. 241-300, 1960.

[5] Conn, A.T., Burgess, S.C. \& Ling, C.S., Design of a parallel crank-rocker flapping mechanism for insect-inspired micro air vehicles, proceedings of the institution of mechanical engineers, part c. Journal of Mechanical Engineering Science (Special Issue), 221(10), pp. 1211-1222, 2007. doi:http://dx.doi.org/10.1243/09544062JMES517

[6] Rieppel, O., The naso-frontal joint in snakes as revealed by high-resolution X-ray computed tomography of intact and complete skulls. Zoologischer Anzeiger, 246(3), pp. 177-191, 2007. doi:http://dx.doi.org/10.1016/j.jcz.2007.04.001

[7] Westneat, M.W. \& Wainwright, P.C. Feeding mechanism of the sling-jaw wrasse, Epibulus insidiator (Labridae; Teleostei): evolution of a novel functional system. Journal of Morphology, 202, pp. 129-150, 1989. doi:http://dx.doi.org/10.1002/jmor.1052020202

[8] Burgess, S.C., King, A. \& Hyde, R., An analysis of optimal structural features in the peacock tail feather. Optics \& Laser Technology, 38, pp. 329-334, 2006. doi:http://dx.doi.org/10.1016/j. optlastec.2005.06.021

[9] Burgess, S.C. \& Pasini, D., Analysis of the structural efficiency of trees. Journal of Engineering Design, 15(2), pp. 177-193, 2004. doi:http://dx.doi.org/10.1080/09544820410001658517

[10] Helfman, G.S., Collette, B.B. \& Facey, D.E., The Diversity of Fishes, Blackwell Science, Inc., Malden, USA, p. 111, 1997.

[11] Grubich, J.R. \& Westneat, M.W., Four-bar linkage modelling in teleost pharyngeal jaws: computer simulations of bite kinetics. Journal of Anatomy, 209, pp. 79-92, 2006. doi:http://dx.doi. org/10.1111/j.1469-7580.2006.00551.x

[12] Westneat, M.W., Alfaro, M.E., Wainwright, P.C., Bellwood, D.R., Grubich, J.R., Fessler, J.L., Clements, K.D. \& Smith, L.L., Local phylogenetic divergence and global evolutionary convergence of skull function in reef fishes of the family Labridae. Proceedings of the Royal Society B, 272, pp. 993-1000, 2005. doi:http://dx.doi.org/10.1098/rspb.2004.3013

[13] Westneat, M.W., Evolution of levers and linkages in the feeding mechanisms of fishes. Inegrative and Comparative Biology, 44, pp. 379-389, 2004. doi:http://dx.doi.org/10.1093/ $\mathrm{icb} / 44.5 .378$

[14] Blake, R.W., Fish Locomotion, Cambridge University Press, Cambridge, UK, p. 124, 1983.

[15] Webb, P.W., Fast start resistance of trout. J Exp Biol, 96, pp. 93-106, 1982. 
[16] Curtin, N.A. \& Woledge, R.C., Efficiency of energy conversion during sinusoidal movement of white muscle fibres from the dogfish scyliorhinus canicula. J Exp Biol, 183, pp. 137-147, 1993.

[17] Wakeling, J.M. \& Johnston, I.A., Muscle power output limits fast-start performance in fish. The Journal of Experimental Biology, 201, pp. 1505-1526, 1998.

[18] Hill, A.V., The heat of shortening and the dynamic constants of muscle. Proc Royal Soc B, 126, pp. 136-195, 1938. doi:http://dx.doi.org/10.1098/rspb.1938.0050

[19] Westneat, M.W., A biomechanical model for analysis of muscle force, power output and lower jaw motion in fishes. Journal of Theoretical Biology, 223, pp. 269-281, 2003. doi:http://dx.doi. org/10.1016/S0022-5193(03)00058-4

[20] Vogel, S., Comparative Biomechanics: Life's Physical World, Princeton University Press: Princeton, p. 401, 2003.

[21] Westneat, M.W., Transmission of force and velocity in the feeding mechanisms of labrid fishes ( teleostei, perciformes). Zoomorphology, 114(2), pp.103-118, 1994. doi:http://dx.doi. org/10.1007/BF00396643

[22] NASA Technical brief GSC-14297, [http://www.techbriefs.com/index.php?option = com staticxt\&staticfile $=/$ Briefs/Aug01/GSC14297.html] .

[23] Alam, H., Apparatus for moving an object in nanometer and method thereof, US, Patent application number: 20100101361, 2010.

[24] Koseki, Y., Koyachi, K., Arai, T. \& Chinzei, K., Remote actuation mechanism for mr-compatible manipulator using leverage and parallelogram - workspace analysis, workspace control, and stiffness evaluation. Proceeding of Robotics and Automation, 1, pp. 652-657, 2003.

[25] Lock, R.J., Vaidyanathan, R., \& Burgess, S.C., Mission based optimization of a biologically inspired multi-modal wing model for aerial-aquatic robotic vehicles. Proceedings of the 11th Conference: Towards Autonomous Robotic Systems (TAROS), pp. 140-147, 2010. 